\title{
Insecticidal Effect of Eucalyptus Essential Oils on Mortalities of Storage Pests of Grains Sitophilus oryzae and Sitophilus granarius in the Region of Tissemsilet Algeria
}

\author{
F. Labdelli, F. Bousmaha, K. Mazrou, M. Moulay, M. Adamou-Djerbaoui, H. Rabahi
}

10.18805/IJARe.A-661

\begin{abstract}
Background: Stored cereals are attacked by pests including Sitophilus, a primary insectpestthat kthe whole grain and destroys the germ. The usual control methods are less efficient and more expensive. The use of essential oils of aromatic plants is more interesting. Eucalyptus is a plant of great medicinal value due to the presence of secondary metabolites.

Methods: In this experimentation that took place during the year 2017, extraction of oils by hydro distillation of eucalyptus was used on insects at different doses by two methods with are ingestion and inhalation. Two species of Sitophylus are morphologically different as they may be different with regard to the use of biopesticide (eucalyptus essential oil), regarding the mortality rate in relation to the duration of treatment

Result: Sitophilus oryzae was more sensitive to this bio-pesticide since it was only after eight (08) hours of treatment that mortality exceeded $50 \%$ by the ingestion method whereas only $6.6 \%$ of mortality was recorded on Sitophilus granarius. Same observation by the inhalation method, $90 \%$ mortality on the third day for Sitophilus oryzae while only $20 \%$ mortality on Sitophilus granarius. So the ingestion method requires fewer products plus a speed in the mortality time.
\end{abstract}

Key words: Cereal, Eucalyptus, Mortality, Oil, Sitophilus.

\section{INTRODUCTION}

Cereals dominate agriculture; they are grown for their grains consumed by man and domestic animals. The storage of cereals is a mandatory operation for their availability throughout the year. Storage problems are caused especially in wet areas due to defective bio-physico-chemical conditions (Multon, 1982). Losses caused by insect pests are similarly reported, resulting in a decrease in the quality and quantity of stored grain. Among storage pesttsthe genus Sitophilus depreciates the grain's nutritional value. Usual costly control methods cause environmental problems.

In developed countries, essential oils currently hold an important placein control systems, their role in plant protection research in some countries of the world are no longer demonstrated (Lahlou, 2004). Essential oils extracted from Eucalyptus globulus have been used for a long time in pharmacy.

The objective of our work was to highlight the insecticidal effect of essential oil extracted from Eucalyptus globulus against Sitophilus granarius and Sitophilus oryzae. These two species are biologically different $(S$. granaries lives for 9 months to 2 years while $S$. oryzae 4 to 7 months) (Delobel and Tran 1993) and morphology (S. oryzae has two spots on each elytra (Balachowsky, 1962) and more polyphagous than $S$. granaries, they are practically together in the same batch of storages this study shows the difference in the level and the mortality time of these two species after use of eucalyptus essential oil against adults.
Department of Natural Sciences and Life, Ibn Khaldoun University, BP 78 Zaaroura, Tiaret, Algeria.

Corresponding Author: F. Bousmaha, Agro-Biotechnology and Nutrition Laboratory in Semi-arid Zone, Ibn Khaldoun University, BP 78 Zaaroura 14000, Tiaret, Algeria.

Email: fleurs_jasmin@yahoo.fr

How to cite this article: Labdelli, F., Bousmaha, F., Mazrou, K., Moulay, M., Adamou-Djerbaoui, M. and Rabahi, H. (2021). Insecticidal Effect of Eucalyptus Essential Oils on Mortalities of Storage Pests of Grains Sitophilus oryzae and Sitophilus granarius in the Region of Tissemsilet Algeria. Indian Journal of Agricultural Research. DOI: 10.18805/IJARe.A-661.

Submitted: 28-05-2021 Accepted: 12-08-2021 Online: 21-08-2021

\section{MATERIALS AND METHODS}

In this experimentation that took place during the year 2017, the harvest of eucalyptus globulus leaves was carried out in one of the gardens at the regionof Tissemsilet in Algeria. The eucalyptus leaves were leaned and dried in the shade and powdered. The powder was stored in paper bags to prevent moisture.

The insect was reared in jars containing the insect from contaminated storage originating from the storage premises. Optimal conditions of development of the insect at the oven were $70 \%$ humidity and $28^{\circ} \mathrm{C}$. In a balloon, we putted $50 \mathrm{~g}$ of vegetable matter (powder), to which we added $500 \mathrm{ml}$ distilled water. The mixture was boiled $\left(100^{\circ} \mathrm{C}\right)$, the vapors 
charged with oil the essential pass in the condenser to condense in a collection ball.

In this way two distinct phases were obtained or the oil supersedes the water. This solution is decanted in a counting bulb where the two phases separate due to the difference in density; as a result the oil is separated from the water. The oils obtained are stored in test tubes surrounded by aluminum foil to protect them from light and kept cool at a temperature of $5^{\circ} \mathrm{C}$. The yield of essential oils is defined as the ratio between the mass of essential oil obtained and the dry mass of the plant material to be treated.

$$
\mathrm{R}=\mathrm{M} 1 / \mathrm{M} 2 \times 100
$$

R: Yield in essential oils expressed in \%.

M1: Mass from the essential oil.

M2: Mass of sample in grams.

Each insect species underwent two different treatments with different doses of eucalyptus oil used as an insecticide. The material used consists of petri dishes $9 \mathrm{~cm}$ in diameter. We introduce each box of wheat grains baste with the essential oil using a micropipette. To reduce the heterogeneity of the behavior of the insect; three repetitions are essential for each dose of treatment. The different doses of essential oils used during the ingestion treatment are respectively D1 $(10 \mu \mathrm{l})$, D2 $(15 \mu \mathrm{l})$, D3 $(20 \mu \mathrm{l})$.In each box 10 adult insects are introduced. A control is indispensable; an insec ted by grains of wheat. The experiment is carried out under an ambient temperature of $24^{\circ} \mathrm{C}$ and a humidity relative of $70 \%$. The observations are made during 8 days from the beginning of the experiment.

Regarding the second method by inhalation, the insects are placed in $250 \mathrm{ml}$ glass jars, a dose of essential oil is deposited on a piece of cotton with a thread on the inside of the lid. The doses used during this phase are higher: they are: $30,40.50 \mu \mathrm{L}$. At the same time, a control is made (cotton without essential oil). 10 adult insects are introduced into each jar which is then quickly closed. Counts of Dead individuals are then carried out after varying exposure times.

\section{RESULTS AND DISCUSSION}

The essential oil characteristics obtained by the hydrodistillation of plant used extract of Eucalyptus from the region of Tissemsilet is light (colorless) with a strong and clear odor. Eucalyptol (1.8-cinceole) is the major constituent of the 70$80 \%$ of oil, with compounds witch are terpene (Bruneton, 1993). The yield of essential oil extracted after hydro distillation was found to be $1.05 \%$. Bruneton (1993) reported the content of Eucalyptus oil is between 0.5 and $3.5 \%$.

Our objective was to determine the insecticidal effect of E. globulus essential oils on S. granarius and S. oryzae. The criterion of oil efficiency is mortality, according to the following formula:

$$
\text { Mortality rate }=\frac{\text { Number of dead individuals }}{\text { Total number of individuals }} \times 100
$$

Regarding the first method which is ingestion, the insect was nourish by grains brushed with different doses.

After two hours of treatment the mortality rate of $S$. oryzae was $0 \%$ for the first two doses while for the third dose it was $66 \%$.After four hours, the mortality rate for the dose D3 has increased to 20\%. After eight hours, the mortality rate reached $50 \%$ for the dose D3, $26.6 \%$ for (D2) and $10 \%$ (D1).

So the LD50 (lethal dose for $50 \%$ of the population) was recorded after ingestion of grains (Fig 1). All mortality was recorded after 24 hours of treatment for a dose of 20il of oil by ingestion while for the second species $S$. granarius the mortality rate required longer than the previous species, it took 8 hours of treatment to reach $6.6 \%$ for D1 et D3 doses.

After one day, the highest mortality rate was $63.3 \%$ to increase on the second and third day to reach 90 and $100 \%$ for the dose (D3) (Fig 1).

After eight (8) hours of treatment the mortality rate reached $6.66 \%$ for the doses (D2) and (D3). It was only in the third day that mortality rates started to reach $16.6 \%$ for (D1) and 30\% eatch for (D2) and (D3). On the fourth and fifth day mortality rates increased significantly to over $50 \%$

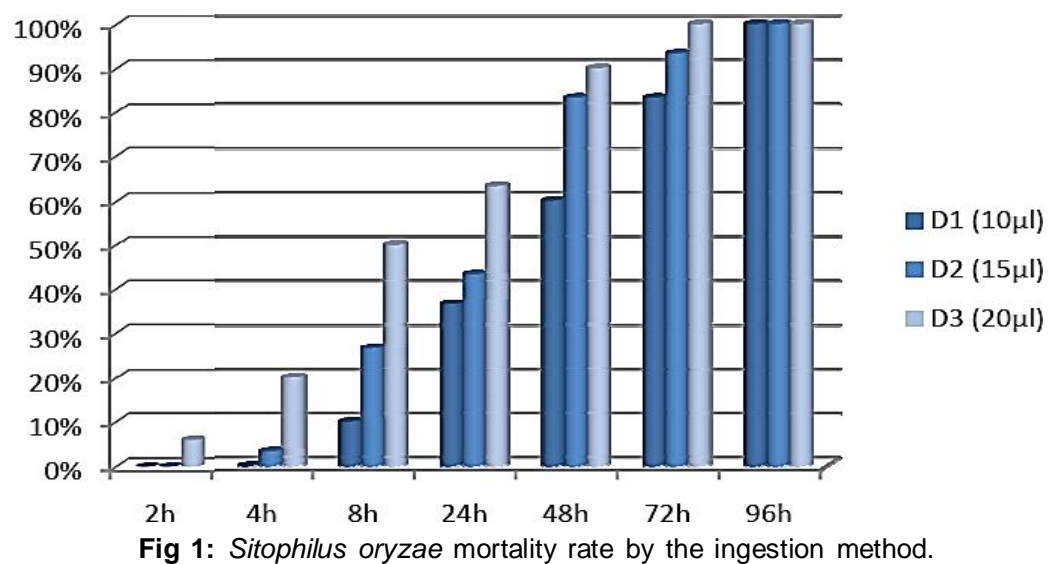


and reached $83.3 \%$. More than $90 \%$ mortality on the sixth day is recorded for the different doses.

On the eighth day the mortality was $100 \%$ for the (D2) and (D3) with regard to the second method (Fig 2). The doses of the inhalation treatment were higher D1, D2, D3 respectively 30.40 and 50 microliters. The mortality rate of S. oryzae after using eucalyptus oil as a biopesticide by this method causes $10 \%$ mortality.

After eight (08) hours the rate increased to $36.6 \%$ for (D3). In twenty-four hours, the mortality rate increased to $63.3 \%$ for (D3) exceeding the DL50, 26.6 for (D2) and 20\% for (D1). On the second day and the third day the mortality rate continued to increase for all the three doses to reach 86.6 and $90 \%$. On the fourth and fifth day the mortalities exceeded $90 \%$ (Fig 3). While for S. granarius the mortalities recorded after the use of inalation begins to increase only after 3 days of treatment to reach only $20 \%$ with the D3 it took 5 days of treatment to arrive the LD50.

No mortality was recorded for the three different doses during two, four and eight hours of treatment. It was only after the first and second days, low mortality could be recorded especially for D2 and D3. On the third day the mortality rate was $20 \%$ for $\mathrm{D} 3,26.6 \%$ for $\mathrm{D} 2$, for $\mathrm{D} 1$ the rate was lower with $3.33 \%$. On the fourth day the mortality rate reached $26.6 \%$ for D3, $40 \%$ for D2 and $16,6 \%$ for D1 at the fifth day the mortality rate (50\%) for the dose D2, $40 \%$ for D3 and $23.3 \%$ for D1. After eighth and tenth day, the mortality rate reached $73.3 \%$ and gradually increased to $80 \%$ on the fifteenth (Fig 4).

Bekhechi et al, (2008) reported the insecticidal effect of Eucalyptus and the results of the present study showed the effect of this oil on the mortality for both the species of Sitophilus. The mortality rate of $S$. oryzae was observed to be high in a very short time compared to $S$. granarius with ingestion treatment. The absence of mortality in the control showed that our test was reliable for the studying the insecticidal effect of the essential oils tested.

With regard to the method of ingestion, $S$. granarius recorded a mortality rate of $3.33 \%$ after four (04) hours of treatment and a rate of $6.66 \%$ and $6.66 \%$ after twenty four (24) hours. On the fourth and fifth day, mortality rates increased to $53 \%$ and $83.3 \%$, respectively. After eight (08) days, the mortality rate was $100 \%$.

While for $S$. oryzae, the oil took effect earlier than that for the other species since after only two (02) hours the mortality rate reached $6.66 \%$ and $50 \%$ after eight $(08)$ hours and after only (02) two days the mortality are $90 \%$ and reached $100 \%$ on the third day. The mortality rate of $S$. granrius is lower than that of $S$. oryzae. As these two species are different morphologically and in the duration of the development cycle (the time to have a generation).

So, the efficiency of the oil on S. oryzae is better than on $S$. granaius, since after 48 hours of use of the oil against S. oryzae, its mortality rate increased to $90 \%$ whereas after

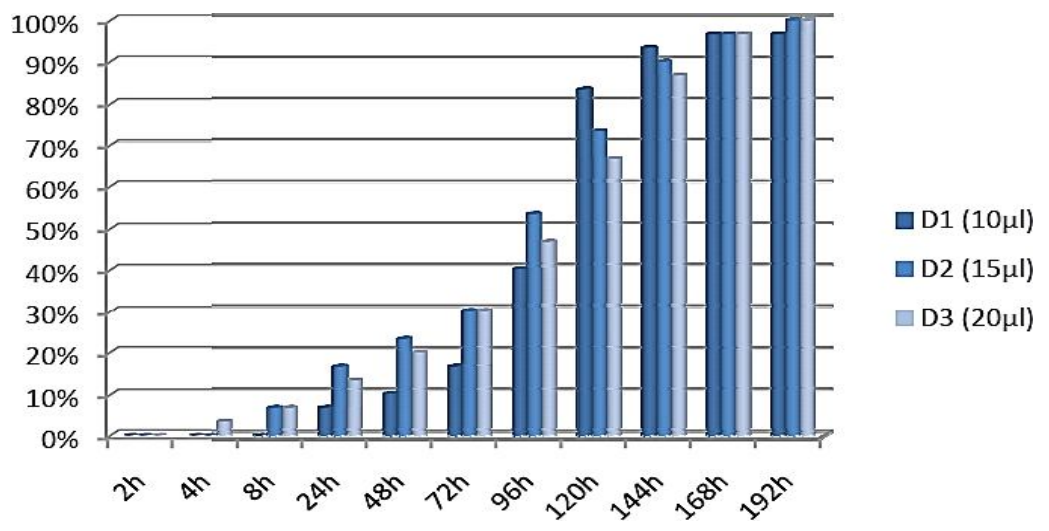

Fig 2: Mortality rate on Sitophilus granarius by the ingestion method.

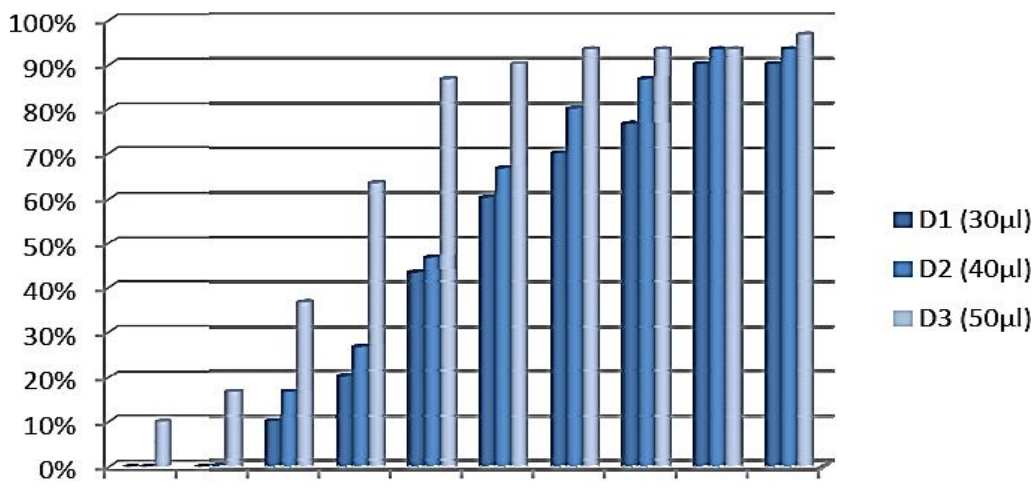

2h $\quad 4 \mathrm{~h} \quad 8 \mathrm{~h} \quad 24 \mathrm{~h} \quad 48 \mathrm{~h} \quad 72 \mathrm{~h} \quad 96 \mathrm{~h} \quad 120 \mathrm{~h} 144 \mathrm{~h} 360 \mathrm{~h}$

Fig 3: Mortality rate on Sitophilus oryzae by the inhalation method. 


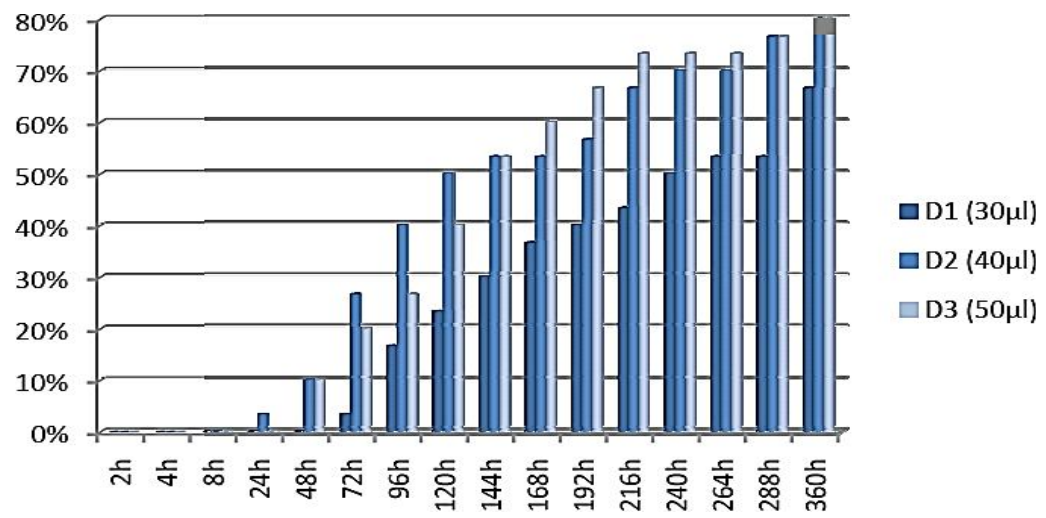

Fig 4: Sitophilus granarius mortality rate by inhalation method.

the same period the mortality of the latter did not exceed $20 \%$. For the inhalation method, the mortality rate for S. orysae are remarkable with values reaching $10 \%$ after two (02) hours of treatment, $36.6 \%$ after eight hours, $63.3 \%$ (a significant value) after one (01) day and exceeded $90 \%$ on the fourth and fifth day.

S. granarius, recorded $3.33 \%$ and $10 \%$ mortality after one and two days respectively. The mortality rate reached $40 \%$ on the fourth $50 \%$ on the fifth day. Eighty per cent mortality could be achieved only after 15 days of treatment It.

The method of inhalation required a larger amount of oil and more time compared to the method of ingestion. The doses used were higher and the effectiveness of the oil on $S$. oryzae was more marked than that on $S$. granarius. $S$. oryzae proved to be more sensitive to oil than $S$. granarius, which was more tolerant resistant.

\section{CONCLUSION}

In recent decades with sustainable development countries find themselves in the obligation to minimize the use of pesticides. So with the use of these biomolecules, the pests will have less resistance and can be compared with lesser cost. This work showed that the use of these biopesticides is promising and reliable because insect mortality was observed with low doses in a shorter. Regarding the ingestion method that required only a small amount of oil, the mortality of Sitophilus oryzae was noticed by two hours of treatment.

Total mortality is achieved necessite three days of treatment; While records only $15 \%$ mortality after 24 hours of treatment for $S$. granarius, total mortality requires 8 days of treatment. So the efficiency of the oil on $S$. oryzae is stronger than on $S$. granarius, with this difference in time and mortality rate the effectiveness of these bio pesticides demonstrates are use in the future.

\section{REFERENCES}

Balachowsky, A.S. (1962). Entomology to agriculture treats. volume I. Coleopteres. Saint German Paris 1070-1099p.

Bekhechi, C., Atik-Bekkara, F., Abdelouahid, D.E. (2008). Composition and antibacterial activities of essential oils of origanum glandulosum of algerie. Phytothérapie. 6: 153-159.

Bruneton, J. (1993). Pharmacognosy, phytochemistry, medicinal plants. Paris, Lavoisier, pp. 623.

Delobel, A. and Tran, M. (1993). Coleoptera of Stored Food Stuffs in Hot Regions, ORSTOM, Paris. pp. 343-350.

Djeddi, S. (2012). Essential oils "mysterious secondary metabolites". Francophone Academic Press. pp. 265.

Lahlou, M. (2004). Methods to study the phytochemistry and bioactivity of essential oils. Phytother. Res. 18: 435-448.

Multon, J.L. (1982). Storage of grains and products oleaginous derivates. Ed: Lavoisier, Paris. 1(2): 576. 